\title{
Continuous Heating System Using Electric Resistance Heating for the Hot Rolling of Stainless Steels
}

\author{
Yasunori ASANO, Takaaki NISHI and Jun YANAGIMOTO"1) \\ Graduate Student, Institute of Industrial Science, The University of Tokyo, Komaba, Meguro-ku, Tokyo $153-8505$ Japan. \\ 1) Institute of Industrial Science, The University of Tokyo, Komaba, Meguro-ku, Tokyo 153-8505, Japan. \\ E-mail: yan@iis.u-tokyo.ac.jp
}

(Received on April 30, 2002; accepted in final form on June 22, 2002)

\begin{abstract}
Electric resistance of metals increases according to the elevation in temperature. Non-uniform temperature distribution in cross-section can be automatically sacrificed if we use electric resistance heating, and uniformly distributed cross-sectional temperature can be easily obtained. A continuous heating system using electronic resistance heating is developed, and its characteristics to the heating of stainless steel are examined through a series of basic experiments. Through the investigation, it has become clear that uniform continuous heating of stainless steel can be realized by proposed heating system. Although the composition of heating system is quite simple, high rate in temperature elevation can be obtained. Also, we can precisely control the temperature distribution in feeding (rolling) direction by continuous electric resistance heating, because temperature of metals can be rapidly changed only by changing the degree of electric current and time to impose electric current.
\end{abstract}

KEY WORDS: continuous heating; electric resistance; rolling; furnace.

\section{Introduction}

Temperature of metal under forming is one of the most important parameter to control forming condition and microstructure of product. Rolling temperature in hot rolling is mainly controlled by heating furnace which locates before hot rolling mills. Annealing temperature should be precisely controlled in continuous annealing process line, in order to obtain desired mechanical properties of product sheet, which will be delivered to sheet forming industries. In addition to two representative examples described above, many characteristics during forming and formed products are influenced by the temperature of metal under forming. Then adequate control of temperature is of great importance in forming, as well as the control of plastic deformation and alloy composition.

Temperature of metal under forming can be changed by combining heating and cooling, and, generally, furnace is used to elevate the temperature. In the furnace heating, preliminary target temperature to be controlled is the temperature inside the furnace. Temperature of metal can be changed by changing temperature of furnace. This means that the temperature control of metal using furnace heating is being conducted in an indirect manner. Due to this reason, uniform heating of metal is extremely difficult with conventional furnace heating system. In addition, it is impossible to change heating temperature of each slab freely, for example, which is delivered to hot rolling.

Also, we can not expect excellent efficiency of fuel consumption, because we have to heat the furnace itself to ele- vate temperature of metal. These problems arise from the nature of indirect heating of the metal. Direct heating of metal may be helpful to realize on-demand heating of metal with uniform temperature distribution with higher efficiency in fuel consumption. Direct heating of metal may be realized using induction heating, but we can not avoid nonuniform temperature distribution after heating.

Electric resistance heating is one of the typical methods of direct heating of metal under forming. Equipment is consisted by current source and electrode, which is much smaller and simpler than that of heating furnace. As electric resistance of metals increases according to the elevation in temperature, more electric current flows in metal portion with lower temperature in the cross-section. Then, non-uniform distribution in temperature can be automatically sacrificed if we use electric resistance heating, and uniformly distributed temperature can be easily obtained. Moreover, temperature of metal could be quickly and freely changed only by changing electric current and heating time. Electric resistance heating has been utilized in materials testing devices, where uniform temperature distribution is strongly requested. ${ }^{1)}$ It is also used to heat stainless steel to manufacture clad sheet, ${ }^{2)}$ or applied to semi-solid forming process $^{3)}$ and powder forming process. ${ }^{4)}$ A continuous heating system using electronic resistance heating was applied to the manufacturing of clad sheet, ${ }^{2)}$ but its basic characteristics, such as the effect of electric current, position of electrodes, number of electrodes to the elevation of temperatures can not be seen in the literature.

Basic characteristics of continuous electric resistance 
heating for the heating of stainless steel are shown and discussed in this paper. A continuous electric resistance heating, using two electrodes as well as three electrodes, is examined through a series of basic experiment, and the rate of temperature elevation and its transient changes are investigated. Based on experimentally obtained results and analyses, new temperature controlling scheme to adjust initial temperature distribution in feeding direction is proposed. Proposed scheme can sacrifice initial non-uniform temperature distribution in rolling direction, by changing position of electrodes and current degree in an adequate manner following basic equation of electric resistance heating. Finally, application of continuous electric resistance heating to microstructure control of stainless steel in hot rolling is demonstrated.

\section{Experimental Conditions and Equipments}

Basic composition of continuous heating system is shown in Fig. 1. Current source generates electric current with low voltage. In this experiment, $V=6.0$ (Volt) is used. Generated electric current is supplied to the metal through electrode. Electrodes used in present investigation are made of Copper JIS-C1020 ( $>99.96 \% \mathrm{Cu})$. Rate of temperature elevation during electric resistance heating can be expressed by Eq. (1). Here, heat dissipation to atmosphere and radiation is neglected. This assumption is reasonable when elevation rate in temperature is rapid enough.

$$
\frac{d T}{d t}=\frac{R}{S^{2} c \rho} I^{2}
$$

Here, $R$ is electrical resistance, $c$ is specific heat, and $I$ is electric current. $S$ is area of cross-section of metal and $\rho$ is density of metal. Needless to say, metal with higher electric resistance $R$ under higher electric current $I$ is favorable to attain effective heating and rapid elevation in temperature. Then, in this investigation, SUS304 stainless steel $(0.08 \mathrm{C}-$ $19.1 \mathrm{Cr}-8.1 \mathrm{Ni}-\mathrm{Fe}$ ) is selected as a testing metal.

Figure 2 shows newly developed electrode to supply electric current to stainless steel. This electrode can rotate freely following the feeding of metal under rolling, so that it could be easily implemented into continuous rolling mill and continuous annealing line. These electrodes are connected with power supply as is shown in Fig. 1, or, they are installed in parallel circuit as is shown in Fig. 3 using three rotating electrode. Rate of temperature elevation of stainless steel in each circuit can be easily controlled by changing electric current in each circuit. Electric current which flows in each circuit could be controlled if we change distances between two pairs of electrodes. Therefore, temperature history of stainless steel, which is passing through three electrodes, can be controlled easily, only by changing electric current and time necessary to pass intervals between a pair of electrodes. More number of electrodes could be used to realize arbitrary temperature history of stainless steel which passes thorough these electrodes, and it may be helpful to control microstructure of product precisely and on demand.

Experimental conditions are shown in Table 1. Power supply with maximum capacity of $300 \mathrm{~A}$ is used in this ex-

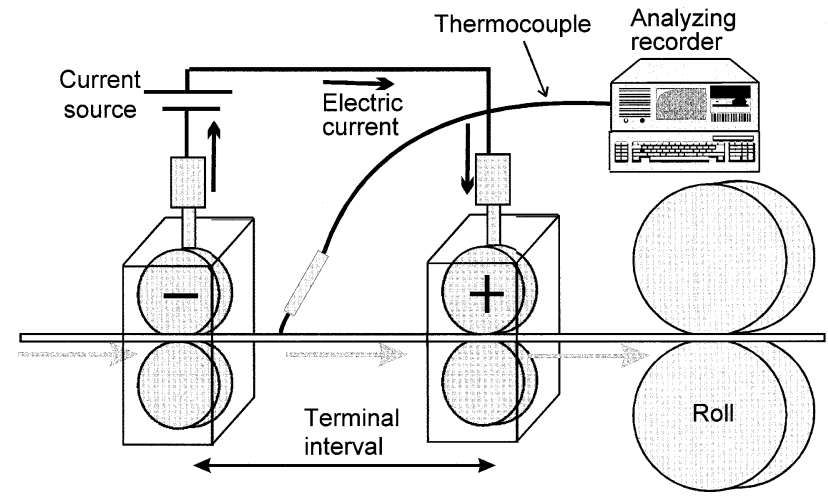

Fig. 1. Basic composition of continuous heating system with two electrodes.
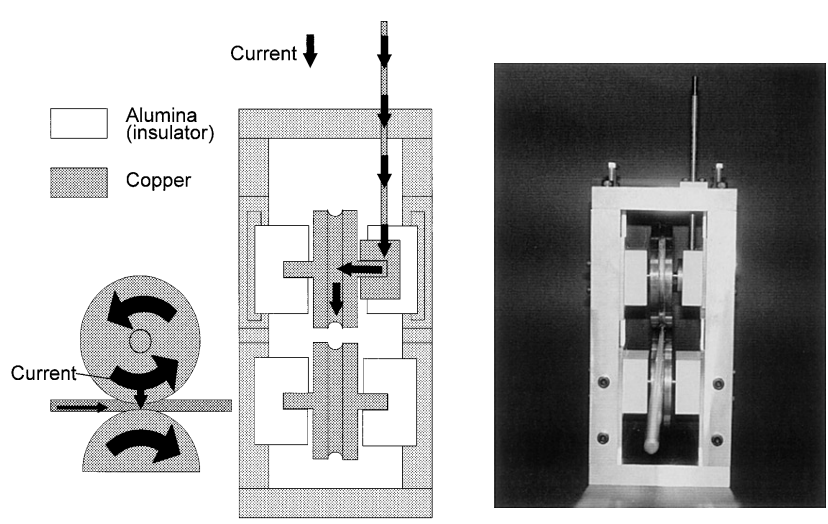

Fig. 2. Electrode used in present investigation.

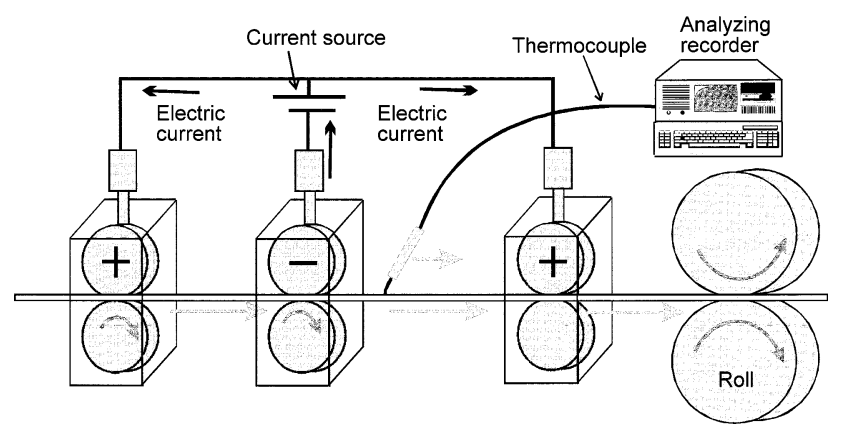

Fig. 3. Basic composition of continuous heating system with two electrodes.

periment. Voltage is $V=6.0$ (Volt), as is described before. Stainless wire rod with diameter of $5.0 \mathrm{~mm}$ is selected as a testing metal, to realize higher elevation rate of temperature. Feeding rate of stainless steel $v$ is around $25 \mathrm{~mm} / \mathrm{s}$. No thermal insulation is applied to the metal when wire rod is fed in longitudinal direction. In addition, $10 \mathrm{~mm}$ diameter wire rod is used to check cross-sectional temperature distribution by electric resistance heating. In this experiment, thermal insulation is made, and wire rod is kept stationary inside the thermal insulating box. Other material parameters are listed also in Table 1. 
Table 1. Experimental conditions and material parameters.
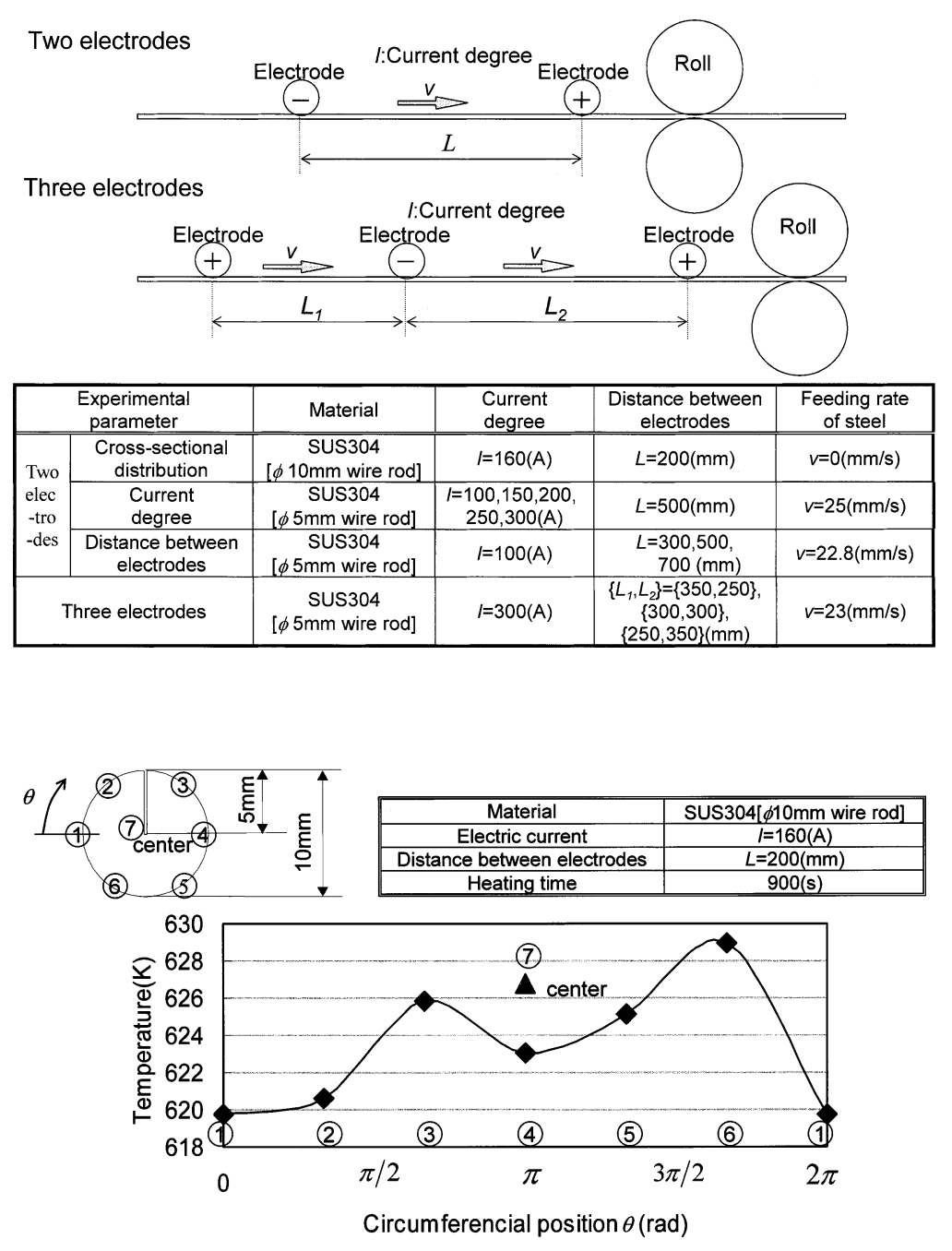

Fig. 4. Cross-sectional distribution of temperature during electric resistance heating.

\section{Experimental Results}

\subsection{Cross-sectional Distribution of Temperature in Electric Resistance Heating}

Cross-sectional distribution of temperature during electric resistance heating is shown in Fig. 4. Position of temperature measurement is also shown in Fig. 4. Distance between two electrodes $L$ is $200 \mathrm{~mm}$, and cross-sectional position of temperature measurement is just at the center of two electrodes. Here in this measurement, as is mentioned before, thermal insulation is made, using ceramic wool and heat insulating box. Stainless steel is stationary inside the box. Thermocouple of class $\mathrm{K}$ with the tolerance of $1 \mathrm{~K}$ is used in temperature measurement. It is clearly shown that temperature of stainless steel uniformly distributes in crosssection, within $10 \mathrm{~K}$. As electric resistance of metals increases according to the elevation in temperature, ${ }^{5)}$ non-uniform distribution in temperature can be automatically sacrificed if we use electric resistance heating, and uniformly distributed temperature can be easily obtained, even though the equipment is quite simple.

\subsection{Continuous Heating Using Two Electrodes}

Figure 5 shows change in temperature for different electric current $I$. Temperature is measured at the center of

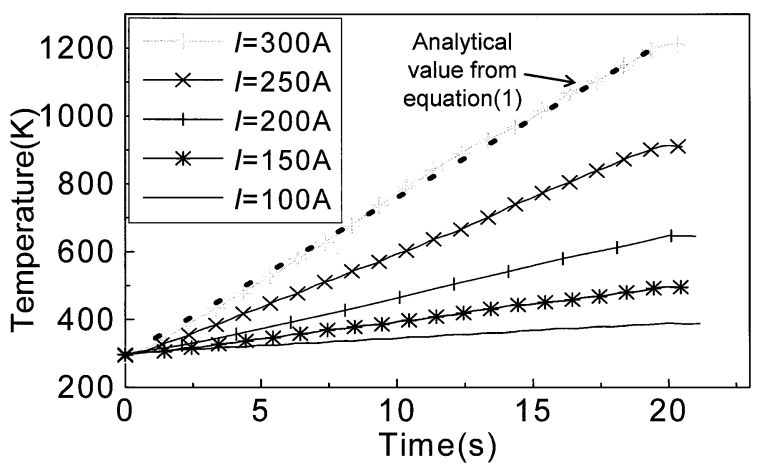

\begin{tabular}{|c|c|c|c|}
\hline Material & Electric current & $\begin{array}{c}\text { Distance between } \\
\text { electrodes }\end{array}$ & $\begin{array}{c}\text { Feeding rate } \\
\text { of steel }\end{array}$ \\
\hline SUS304[ $\phi 5 \mathrm{~mm}$ wire rod] & $l=100,150,200,250,300(\mathrm{~A})$ & $L=500(\mathrm{~mm})$ & $v=25(\mathrm{~mm} / \mathrm{s})$ \\
\hline
\end{tabular}

Fig. 5. Change in temperature for the different electric current.

cross-section using thermocouple, as was illustrated in Fig. 1. Heat insulation is not conducted in this experiment, because stainless steel moves continuously during experiment. Distance between two electrodes $L$ is $500 \mathrm{~mm}$. As the feeding rate of stainless steel $v$ is $25 \mathrm{~mm} / \mathrm{s}$, time to elevate the temperature $L / v$ is about $20 \mathrm{~s}$. Then the temperature of stainless steel stops to elevate after this time, as is shown in 
Fig. 5. It is clearly shown that temperature elevates almost linearly, and rate of temperature elevation is dependent to electric current $I$. Linear elevation in temperature is realized when the current density is high enough, although self sacrificing in cross-sectional temperature also takes place. From Eq. (1), rate of temperature elevation will be $46.6 \mathrm{~K} / \mathrm{s}$ when $I=300 \mathrm{~A}$, as is shown by broken line in Fig. 5 . Experimental value agrees well with analytical value, because temperature is measured at the center of cross-section where effect of heat dissipation can be approximately neglected.

Figure 6 shows change in temperature for different value of distances between electrodes $L$. Also in this case, rate of temperature elevation could be estimated using Eq. (1). More important is the fact that temperature of stainless steel under continuous heating could be controlled by electric current $I$ as well as distance between electrodes $L$ for the given value of feeding rate $v$, or their combination. The position of electrodes could be changed freely, if we need to change the heating position of stainless steel. Cross-sectional distribution of temperature can be uniformly controlled by electric resistance heating, as was shown in Fig. 4 . In addition, adequate control of electric current $I$ and distance between electrodes $L$ can be effective to control the longitudinal temperature distribution during continuous heating.

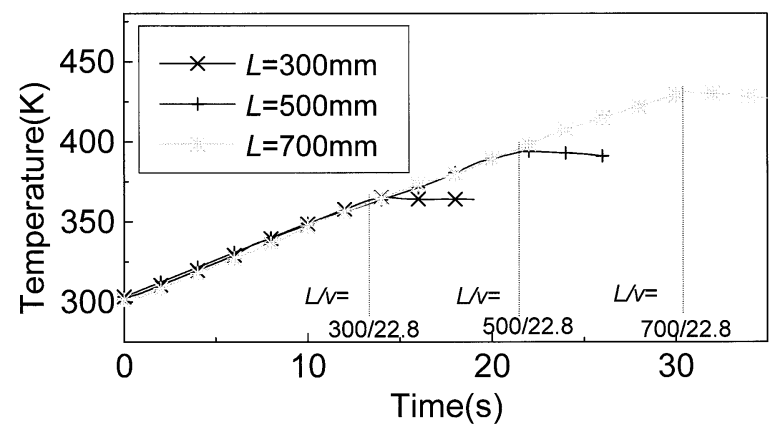

\begin{tabular}{|c|c|c|c||}
\hline Material & Electric current & $\begin{array}{c}\text { Distance between } \\
\text { electrodes }\end{array}$ & $\begin{array}{c}\text { Feeding rate } \\
\text { of steel }\end{array}$ \\
\hline SUS304[ $\phi 5 \mathrm{~mm}$ wire rod] $]$ & $l=100(\mathrm{~A})$ & $L=300,500,700(\mathrm{~mm})$ & $v=22.8(\mathrm{~mm} / \mathrm{s})$ \\
\hline
\end{tabular}

Fig. 6. Change in temperature for the different value of distances between electrodes.
Electric resistance heating is, of course, usable to elevate the temperature of metal from room temperature to hot forming temperature. Also, it is also usable to adjust the distributed temperature of steel in rolling direction to uniform distribution. Heating in furnace usually cause temperature distribution in rolling direction as well as in width direction. Temperature distribution in rolling direction, which may be caused by skid rails in furnace for example, ${ }^{6}$ results in abrupt change in flow stress, rolling force and final microstructure. Figure 7 shows two initial temperature distributions assumed for the following numerical case studies. Temperature controlling scheme using moving electrodes is proposed in the followings.

If temperature sensor detects decrease in metal temperature, distance between electrodes is widened in order to increase time for heating, as is shown in Fig. 6. If temperature is elevated, distance should be decreased. We could choose which electrode should be moved to increase or decrease distance between two electrodes. If the position of electrode in downstream becomes too close to rolling mill, both electrodes are moved upstream with slight elevation of electric current, because of the increase in relative feeding rate of wire rod versus electrodes. Coordinate system to explain positions of anode and cathode is explained by Fig. 8. Special coordinate system, denoted by $x$, is used to express the position of anode and cathode. On the contrary, material coordinate $X$ is used to explain temperature distribution of metal before and after electric resistance heating. The tail of metal is the origin of material coordinate $X$, as is shown in Fig. 8.

Optimized position of electrodes and electric current, which are changing in time, is shown in Fig. 9, for case 1 of Fig. 7. Here, feeding rate of stainless steel is $20 \mathrm{~mm} / \mathrm{s}$. Inverse analysis of Eq. (1) is conducted to obtain transient change in position of electrodes and electric current. Transient position of electrodes, which is shown in Fig. 9, is schematically illustrated in Fig. 10. Anode begins to move with synchronized velocity of wire rod, that is 20 $\mathrm{mm} / \mathrm{s}$, after top of metal enters into electrodes at $t=0.0(\mathrm{~s})$. When distance between electrodes becomes optimized position to elevate temperature of wire rod at $t=25.0(\mathrm{~s})$, anode becomes stationary. At $t=75.0(\mathrm{~s})$, wire rod with

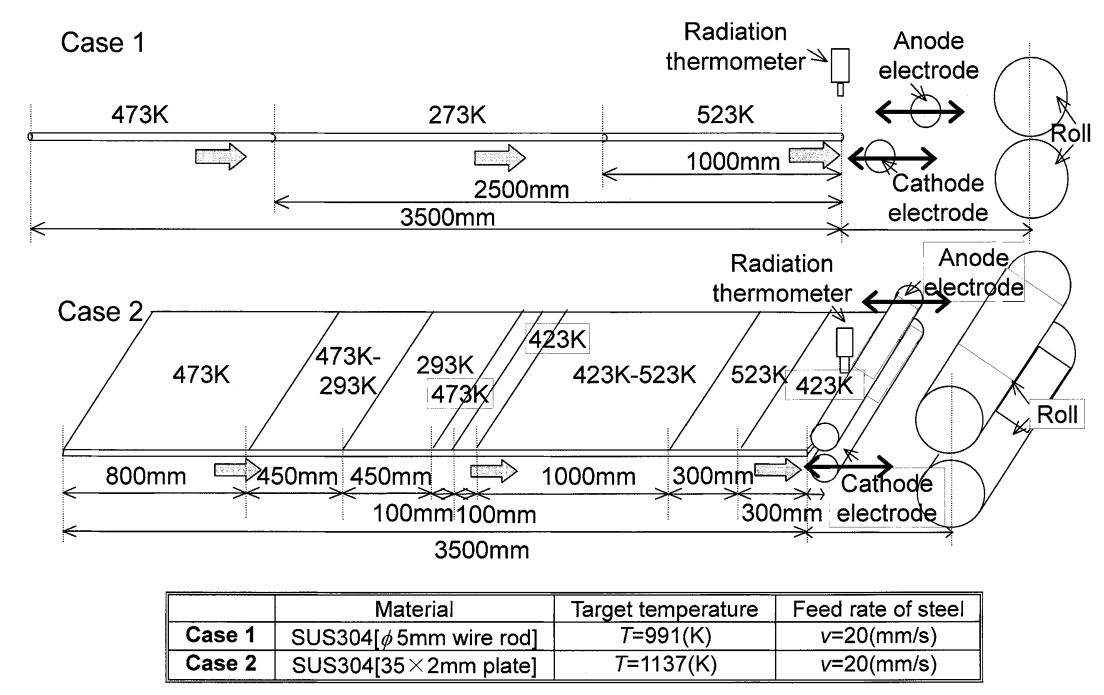

Fig. 7. Initial temperature distributions assumed for the following numerical case studies. 


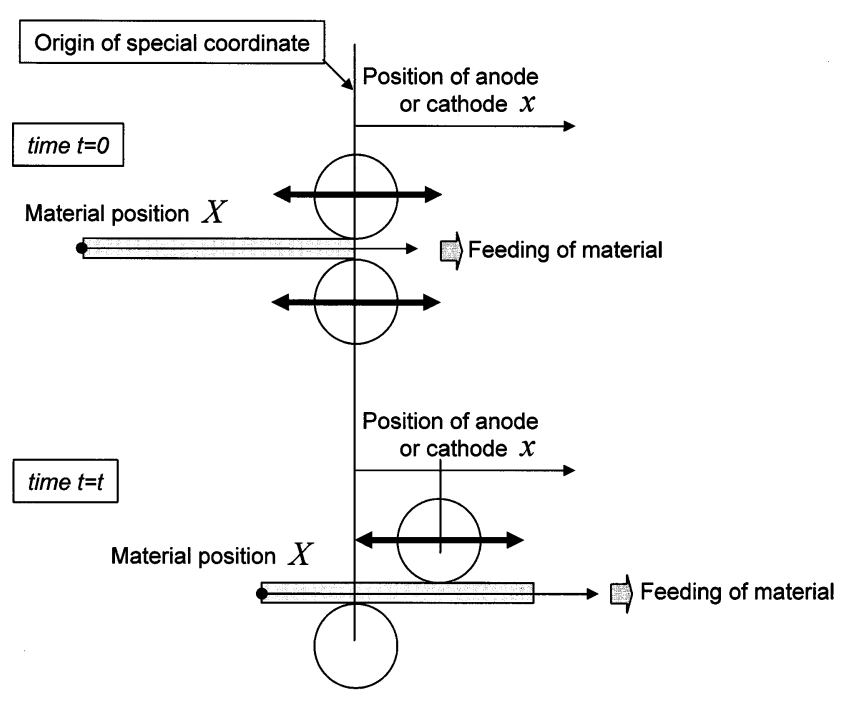

Fig. 8. Coordinate system to explain positions of anode and cathodes, and material position. lower temperature comes close to anode (please see Fig. 7). Then, anode is moved again to downstream to increase heating time, until optimized heating time for given feeding rate $v=20(\mathrm{~mm} / \mathrm{s})$ is attained for cooled portion of moving wire rod at $t=88.3(\mathrm{~s})$. At $t=124.0$ (s), wire rod with higher temperature enters into circuit so that distance between electrodes is decreased by changing position of cathode to downstream. As both electrodes become closer to rolling mill, they are moved back to upstream with the change in electric current corresponding to the increase in relative velocity of electrodes to wire rod. Same controlling scheme of electrodes position and electric current can be adapted to more complicated temperature distribution as is shown in Fig. 11.

It can be seen that uniform distribution of metal in longitudinal direction could be obtained by continuous electric resistance heating even for distributed initial temperature, when electrode positions and electric current are adequately controlled using Eq. (1). This controlling scheme using
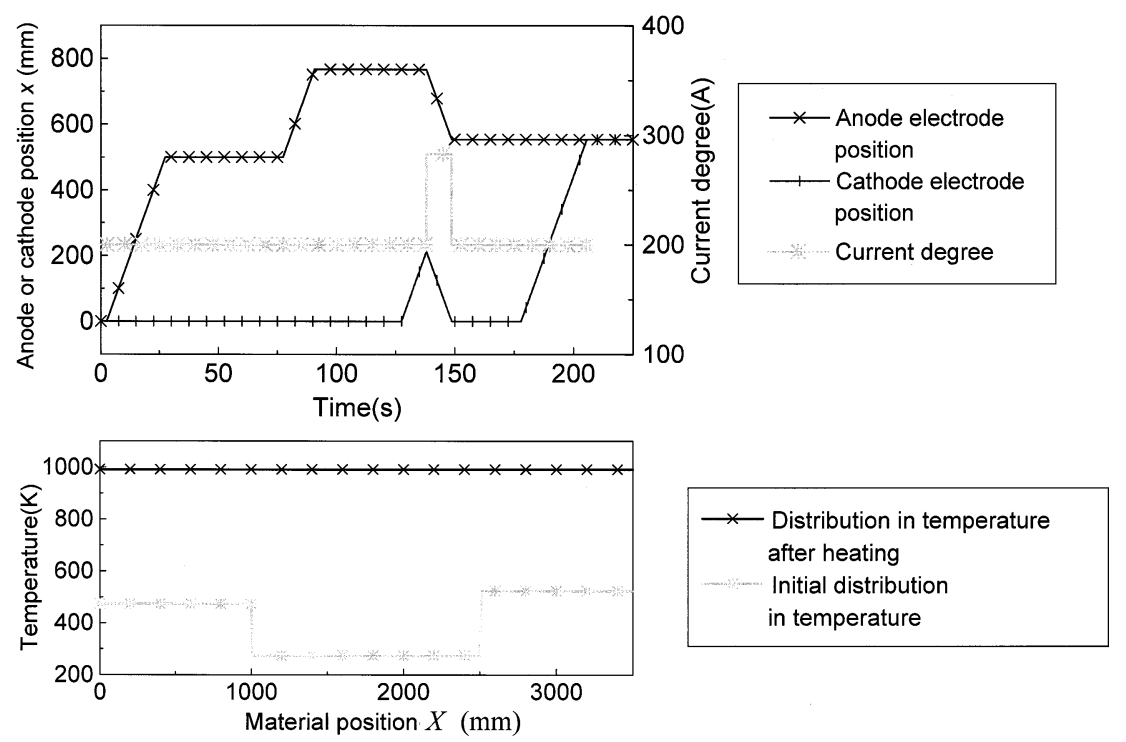

Fig. 9. Transient change in position of electrodes, electric current and final temperature distribution, for case 1.

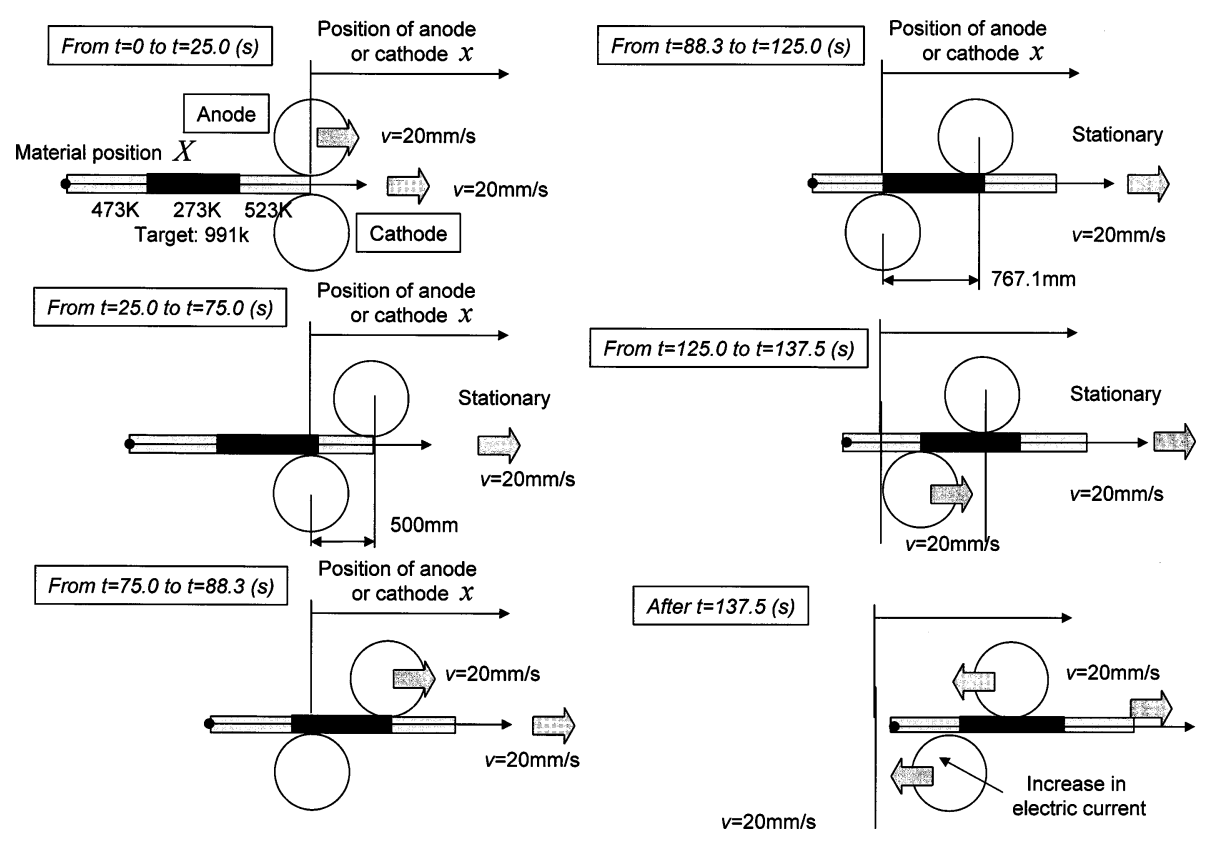

Fig. 10. Schematic illustration of electrode position for case 1 . 

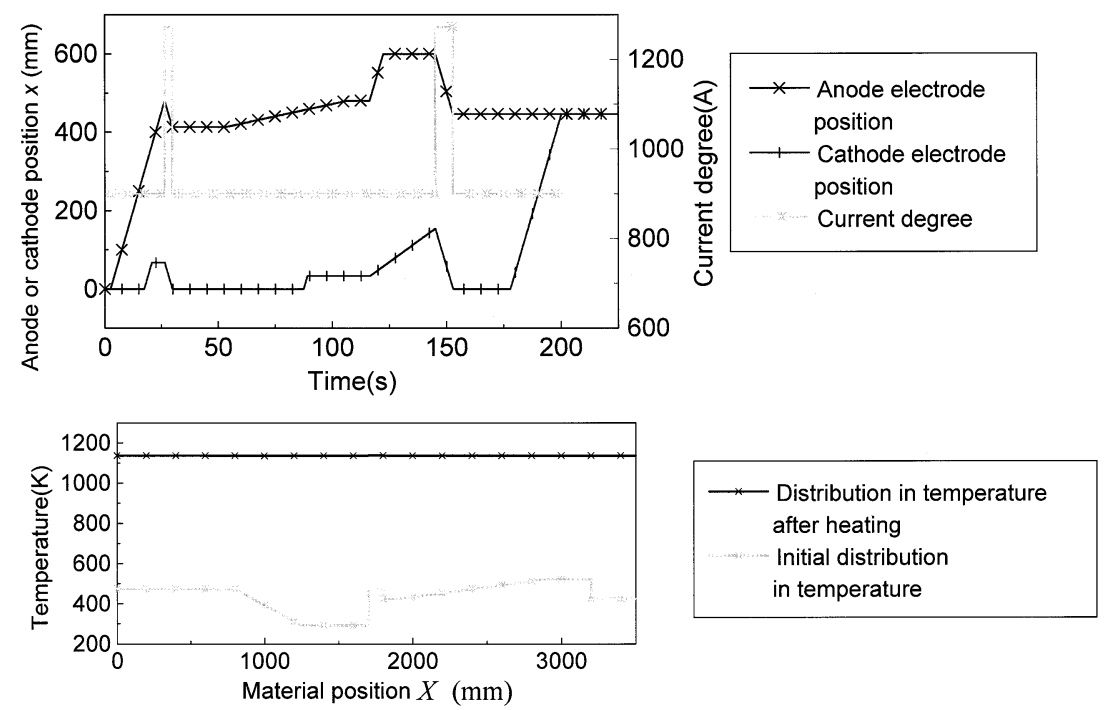

Fig. 11. Transient change in position of electrodes, electric current and final temperature distribution, for case 2 .
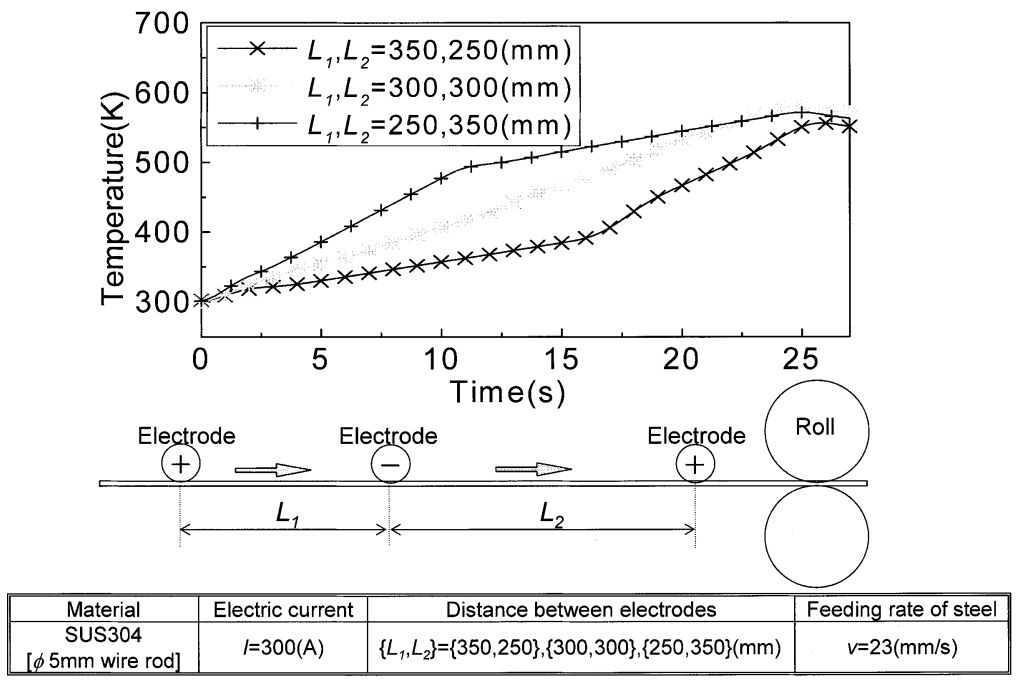

Fig. 12. Transient change in temperature in continuous electric resistance heating with three electrodes.

Table 2. Rolling conditions.

\begin{tabular}{|c|c|c|c|c|c|}
\hline Material & Electric current & $\begin{array}{c}\text { Distance between } \\
\text { electrodes }\end{array}$ & $\begin{array}{c}\text { Feeding rate } \\
\text { of steel }\end{array}$ & $\begin{array}{c}\text { Rolling } \\
\text { temperature }\end{array}$ & $\begin{array}{c}\text { Rolling } \\
\text { reduction }\end{array}$ \\
\hline $\begin{array}{c}\text { SUS304 } \\
{[\phi 5 \mathrm{~mm} \text { wire rod }]}\end{array}$ & $l=308(\mathrm{~A})$ & $L=500(\mathrm{~mm})$ & $v=28(\mathrm{~mm} / \mathrm{s})$ & $T=1022(\mathrm{~K})$ & $46 \%$ \\
\hline $\begin{array}{c}\text { SUS304 } \\
{[\phi 5 \mathrm{~mm} \text { wire rod }]}\end{array}$ & $l=308(\mathrm{~A})$ & $L=500(\mathrm{~mm})$ & $v=20(\mathrm{~mm} / \mathrm{s})$ & $T=1322(\mathrm{~K})$ & $46 \%$ \\
\hline $\begin{array}{c}\text { SUS304 } \\
\text { S } \mathrm{mmm} \text { wire rod }]\end{array}$ & $\mathrm{l}=308(\mathrm{~A})$ & $L=500(\mathrm{~mm})$ & $v=20(\mathrm{~mm} / \mathrm{s})$ & $T=1322(\mathrm{~K})$ & $56.4 \%$ \\
\hline
\end{tabular}

wider electrode or divided electrode, which is shown in Fig. 7, can be used to control sheet temperature just before rolling or annealing uniformly in rolling direction as well as width direction.

\subsection{Continuous Heating Using Three Electrodes}

Construction of heating system using three electrodes was shown in Fig. 3. This system can be applied to control temperature history of every position of metal during continuous heating. Figure 12 shows transient change in temperature during continuous heating obtained by experiment. We can see that combination of electric currents which flows in parallel circuit can change the temperature history, as is easily estimated from Eq. (1).

\subsection{Change in Microstructure after Continuous Heat- ing and Succeeding Rolling}

Heated wire rod is rolled by rolling mill just after second electrode. Temperature of stainless wire rod is controlled by electric resistance heating as is listed in Table 2. Here, temperature before rolling is $1322 \mathrm{~K}$ and $1022 \mathrm{~K}$, and rolling speed $v$ is $20 \mathrm{~mm} / \mathrm{s}$ or $28 \mathrm{~mm} / \mathrm{s}$. Flat roll is used to roll round wire rod with height reduction of $46 \%$ and $56 \%$. Rolled bar is air cooled, and microstructure after cooling is observed.

Figure 13 shows change in microstructure after continuous heating and rolling. Deformed grains are observed when rolling temperature is $1022 \mathrm{~K}$, but recrystallized 


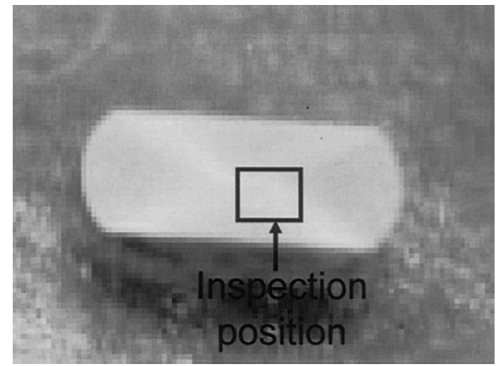

Material section

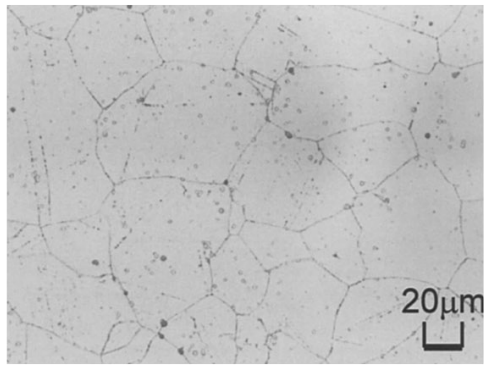

SUS304 material before heating

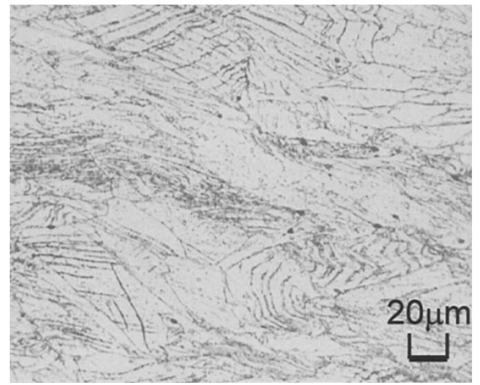

$v=28 \mathrm{~mm} / \mathrm{s} \quad T=1022 \mathrm{~K} 46 \%$
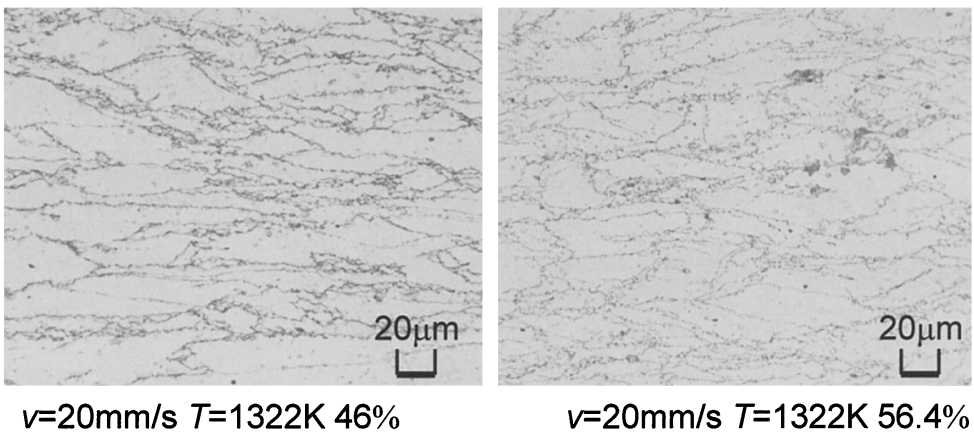

$v=20 \mathrm{~mm} / \mathrm{s} \quad T=1322 \mathrm{~K} 56.4 \%$

Fig. 13. Change in microstructure after continuous heating and rolling.

grains are observed when rolling temperature is $1322 \mathrm{~K}$. Moreover, finer grains could be seen when imposed reduction is higher. As temperature could be controlled precisely using proposed heating and rolling equipment, it could be helpful to realize precise control of microstructure of stainless steel. ${ }^{7-10)}$ Microstructure control of austenitic stainless steel is really important because SUS304 steel does not exhibit microstructure change due to phase transformation.

\section{Conclusion}

Basic characteristics of continuous electric resistance heating are investigated. Continuous heating with two rotating electrode is helpful to control temperature distribution of stainless steel in rolling direction as well as that in crosssection. We can also adjust initial longitudinal temperature distribution of metal to uniform one, by controlling position of electrodes and electric current. Moreover, continuous electric resistance heating using three electrodes may be helpful to control temperature history of each point of metal before rolling or annealing.

Temperature of metal under hot forming is one of the dominant parameter to be controlled. Its precise control will be requested more, because precise control of microstructure requires precise control of temperature history.
Of course, it is important from the viewpoint of geometry control, because temperature distribution may result in variation in rolling force. Continuous electric resistance heating can be one candidate of new heating system to answer these requirements, because it can be realized with simple equipment and it can directly change the temperature of metal under forming.

\section{REFERENCES}

1) Greeble 3800 Catalogue, Dynamic Systems Inc., New York, (2002).

2) K. Hamada, K. Isaka, S. Iwasaki, Y. Yonemitsu, T. Hattori and M. Nakano: CAMP-ISIJ, 11 (1998), No. 2, 368.

3) M. Shiomi, S. Onishi and K. Osakada: Proc. of the 50th Japanese Joint Conf. on Technology of Plasticity, JSTP, Tokyo, (1999), 429.

4) T. Mochizuki, M. Mikami and T. Goto: Proc. of the 47th Japanese Joint Conf. on Technology of Plasticity, JSTP, Tokyo, (1996), 245.

5) Stainless Handbook, ed. by M. Hasegawa, Nikkan-Kogyo Shinbunsha, Tokyo, (1979), 110.

6) Y. Suzuki, M. Okada and T. Kitamura: CAMP-ISIJ, 10 (1997), No. 2, 396.

7) D. R. Barraclough and C. M. Sellars: Met. Sci., (1979), 257.

8) Y. Saito, T. Sakai, F. Maeda and K. Kato: Tetsu-to-Hagané, 72 (1986), No. 7, 799.

9) Y. Saito, T. Sakai, K. Takeda and K. Kato: Tetsu-to-Hagané, 73 (1987), No. 9, 1146.

10) M. Maki, K. Akasaka, K. Okuno and I. Tamura: Tetsu-to-Hagané, 66 (1980), No. 10, 1659. 